\title{
Simple or complex? Consumer response to display signs ${ }^{1}$
}

\author{
Melinda Knuth \\ Doctoral Student \\ Department. of \\ Horticultural Sciences, \\ Texas A\&M University \\ melindaknuth@tamu.edu
}

\author{
Bridget K. Behe* \\ Professor \\ Department of \\ Horticulture, \\ Michigan State University
}

behe@msu.edu

\section{Patricia T. Huddleston}

Professor

Department of Advertising

\& Public Relations,

Michigan State University

huddles2@msu.edu

\section{INTRODUCTION}

The retail environment can overwhelm consumers with visual cues such as merchandise, display fixtures, and signage. Signage is an important marketing communication tool which may influence and persuade consumers at the point of purchase (Kellaris and Machleit 2016). For unpackaged or minimally packaged goods (e.g. plants, apparel, produce), signs can facilitate the buying decision by providing product information that may not be readily discernable by simply viewing the product. Yet, what is the best level of signage information to motivate a purchase, without overwhelming consumers? Scant work has investigated retail sign complexity and its influence on purchase intention. In a study of print advertisements, Pieters et al. (2010) classified traditional measures of visual complexity as feature complexity; their research indicates that visual complexity, composed of both feature and design complexity, greatly differed in their impact on visual attention and attitude toward the ad. While increased feature complexity had mixed results on favorable evaluations, increased design complexity had a more consistent correlation with longer gazes and more favorable attitudes toward the visual display (Pieters et al.). Using those findings as the motivation for the present study, our goal was to investigate the role of sign complexity on likeliness to buy. We speculate that complexity will play a role in visual attention, sign attractiveness, and purchase intention.

\section{LITERATURE REVIEW}

\section{Visual complexity}

Perceived complexity, a subjective property of signage, is an evaluative label that consumers might attribute to a sign and may impact how consumers cognitively process the information presented (Kellaris and Machleit 2016).

\footnotetext{
${ }^{1}$ Funding for this study was provided by Metro-Detroit Flower Growers Association. Technical assistance by Lynne Sage was invaluable to completing this study.
}

\section{Abstract /}

Retail signage provides information from the marketer to facilitate product purchase. An increase in sign information creates greater sign complexity, which raises the question: for consumer product choices, what quantity of information is helpful versus overwhelming? We hypothesize that consumers would allocate more visual attention to complex signs and that sign complexity would be a predictor of likeliness to buy (LTB). Five experts rated 105 real garden center signs for complexity and five low, moderate, and highcomplexity signs were selected for the study. Signs were incorporated into Tobii X1 Light Eye Tracker software, where 85 non-student subjects rated sign attractiveness and LTB from a display containing that sign. Subjects allocated greater visual attention (higher fixation count and longer total fixation duration) to more complex signs, which were also rated as most attractive. Initial regression results showed sign attractiveness and fixation count were positive predictors of LTB, while complexity and total fixation duration were inversely related to LTB. Mediation analysis showed that fixation duration fully mediates fixation count impact on purchase intention. Results suggest that informationrich messaging in high complexity signs, while seen as attractive, may give consumers too much information and higher cognitive load, which makes decision-making more difficult.

\section{Keywords /}

attractiveness; consumer; survey; complexity; retail sign 
Processing fluency refers to the "subjective evaluation of how easily a stimulus is processed," and this concept describes how people cognitively monitor the mental effort required for processing a stimulus (Orth and Crouch 2014, 526; Schwarz 2004). Visual complexity theory helps to explain the mechanism behind processing fluency and explains how "visual input interacts with the perceiver to generate behavior and experience" (Donderi 2006, 84). Berlyne's (1974) aesthetic theory proposes an inverted U relationship of visual complexity with consumer response; the inverted U-curve depicts mid-range visual complexity as the most appealing and capturing the greatest consumer attention (Berlyne 1974; Tuch et al. 2009). In other words, moderately complex images may be more appealing and command more visual attention than simpler or more highly complex images.

Table 1 summarizes the current empirical literature on complexity with regards to design, purchasing intent, functionality, and cognitive processing and the inclusion of images. While many of the studies included images, not all did. Three assessed purchase intention and one measured purchase consideration. One study included a construct similar to attractiveness: aesthetic appeal. None of the literature in this review investigated the complexity of signs focusing instead on webpages, print advertisements, product images, product descriptions, brand logos, and shopping environments. The degree of complexity varied depending on the stimuli being observed. Complexity had an impact on purchase intent in these four studies: Anderson and Jolson (1980); Geissler et al. (2006); Puškarević et al. (2016); and Putrevu et al. (2004).

\section{Simple Designs}

Advertising managers have traditionally shown a preference for simplicity in advertisements, as less complex stimuli are generally easier to process, resulting in higher fluency (Anderson and Jolson 1980; Shuptrine and McVicker 1981; Janiszewski and Meyvis 2001; Reber, Schwarz, and Winkielman 2004; Reber, Wurtz, and Zimmermann 2004). Several studies have analyzed consumer responses to design complexity, for example Orth and Crouch (2014) demonstrate that lower complexity enhances the perceived attractiveness of products and packages and Eytam et al. (2017) find that the majority of subjects ( $75 \%)$ rated simple designs as easiest to use but lower in functionality. Therefore, a bifurcation emerges: simplicity in design is to remove as many unnecessary elements as possible, yet the reduced functionality is not always appreciated by consumers (Berlyne 1974; Thompson et al. 2005). Simple designs may be easier to process and be most attractive but may not necessarily provide sufficient information, nor evoke the greatest likeliness to buy.

\section{Medium and High Complexity Designs}

Increasing the design complexity of a visual message is correlated with increased curiosity and sustained visual attention (Pieters et al. 2010). Moderate complexity has been associated with maximum appeal for message designs (Berlyne 1974; Geissler et al. 2006). Although medium complexity is generally preferred, lower levels of perceived complexity have been associated 
Table 1 / Complexity Literature

\begin{tabular}{|c|c|c|c|c|}
\hline Reference & $\begin{array}{l}\text { Dependent } \\
\text { Variable }\end{array}$ & $\begin{array}{c}\text { Level of } \\
\text { Complexity } \\
\text { Measure }\end{array}$ & Finding & $\begin{array}{c}\text { Images } \\
\text { Included }\end{array}$ \\
\hline $\begin{array}{l}\text { Anderson \& } \\
\text { Jolson, } 1980\end{array}$ & $\begin{array}{c}\text { Purchase } \\
\text { Consideration }\end{array}$ & $\begin{array}{c}\text { Nontechnical } \\
\text { Partially } \\
\text { technical } \\
\text { Technical }\end{array}$ & $\begin{array}{l}\text { Partially } \\
\text { technical had } \\
\text { greatest } \\
\text { purchase intent; } \\
\text { Technical } \\
\text { second most } \\
\text { purchase intent }\end{array}$ & Yes \\
\hline $\begin{array}{l}\text { Chassy et al., } \\
2015\end{array}$ & $\begin{array}{c}\text { Fixation Count, } \\
\text { aesthetic } \\
\text { appraisal }\end{array}$ & $\begin{array}{l}\text { Likert Scale } \\
\text { from } 1 \text { to } 9\end{array}$ & $\begin{array}{l}\text { Highly complex } \\
\text { images were } \\
\text { more preferred; } \\
\text { moderately } \\
\text { complex images } \\
\text { were most } \\
\text { aesthetically } \\
\text { appealing }\end{array}$ & Yes \\
\hline $\begin{array}{l}\text { Dellaert \& } \\
\text { Stremersch, } 2005\end{array}$ & $\begin{array}{c}\text { Mass } \\
\text { Customization to } \\
\text { Consumer }\end{array}$ & $\begin{array}{c}\text { Low } \\
\text { Moderate } \\
\text { High }\end{array}$ & $\begin{array}{l}\text { Complexity had } \\
\text { negative effect } \\
\text { on } \\
\text { customization }\end{array}$ & Yes \\
\hline $\begin{array}{l}\text { Eytam et al., } \\
2017\end{array}$ & $\begin{array}{l}\text { Choice for Users } \\
\text { and Consumers }\end{array}$ & $\begin{array}{c}\text { Simple } \\
\text { Medium } \\
\text { Complex }\end{array}$ & $\begin{array}{l}\text { Medium } \\
\text { complexity was } \\
\text { most preferred } \\
\text { for both Users } \\
\text { and Consumers }\end{array}$ & Yes \\
\hline $\begin{array}{l}\text { Geissler et al., } \\
2006\end{array}$ & Purchase Intent & $\begin{array}{c}\text { Least } \\
\text { Moderate } \\
\text { More Complex }\end{array}$ & $\begin{array}{l}\text { Moderate } \\
\text { complexity had } \\
\text { highest purchase } \\
\text { intent }\end{array}$ & Yes \\
\hline $\begin{array}{l}\text { Goodman \& } \\
\text { Irmak, } 2013\end{array}$ & $\begin{array}{c}\text { Product } \\
\text { satisfaction }\end{array}$ & $\begin{array}{c}\text { Low (Feature } \\
\text { Usage) } \\
\text { Average } \\
\text { High }\end{array}$ & $\begin{array}{l}\text { Low complexity } \\
\text { had highest } \\
\text { product } \\
\text { satisfaction }\end{array}$ & Yes \\
\hline Janiszewski \& & Single-meaning & Likert Scale 1 to & Single-meaning: & Yes \\
\hline Meyvis, 2001 & $\begin{array}{c}\text { Stimuli } \\
\text { Multiple- } \\
\text { meaning Stimuli }\end{array}$ & 7 & $\begin{array}{l}\text { Low complexity } \\
\text { preferred } \\
\text { Multiple- } \\
\text { meaning }\end{array}$ & \\
\hline
\end{tabular}


Table 1 / cntd.

\begin{tabular}{|c|c|c|c|c|}
\hline & & & $\begin{array}{l}\text { Stimuli: High } \\
\text { complexity } \\
\text { preferred }\end{array}$ & \\
\hline Lavie, 2000 & $\begin{array}{c}\text { Mean reaction } \\
\text { times }\end{array}$ & $\begin{array}{l}\text { Low } \\
\text { High }\end{array}$ & $\begin{array}{l}\text { Low requires } \\
\text { less prime } \\
\text { response time }\end{array}$ & No \\
\hline Orth et al., 2016 & $\begin{array}{l}\text { Shopping } \\
\text { experience }\end{array}$ & $\begin{array}{c}\text { Low } \\
\text { Moderate } \\
\text { High }\end{array}$ & $\begin{array}{l}\text { Low complexity } \\
\text { had highest } \\
\text { shopping } \\
\text { experience }\end{array}$ & Yes \\
\hline $\begin{array}{l}\text { Pieters et al., } \\
2010\end{array}$ & $\begin{array}{c}\text { Attitude towards } \\
\text { the Ad }\end{array}$ & $\begin{array}{c}\text { Low } \\
\text { Moderate } \\
\text { High }\end{array}$ & $\begin{array}{l}\text { High complexity } \\
\text { had greatest } \\
\text { attitude towards } \\
\text { ad }\end{array}$ & Yes \\
\hline $\begin{array}{l}\text { Puškarević et al. } \\
2016\end{array}$ & Purchase Intent & $\begin{array}{c}\text { Figuration } \\
\text { No Figuration }\end{array}$ & $\begin{array}{l}\text { Figuration led to } \\
\text { greatest } \\
\text { purchase intent }\end{array}$ & $\begin{array}{l}\text { Some stimuli } \\
\text { had images, } \\
\text { some did not }\end{array}$ \\
\hline $\begin{array}{l}\text { Putrevu et al., } \\
2004\end{array}$ & Purchase Intent & $\begin{array}{c}\text { Likert Scale } 1 \text { to } \\
7\end{array}$ & $\begin{array}{l}\text { High complexity } \\
\text { had highest } \\
\text { purchase intent }\end{array}$ & Yes \\
\hline $\begin{array}{l}\text { Shuptrine \& } \\
\text { McVicker, } 1981\end{array}$ & $\begin{array}{c}\text { Education level } \\
\text { of Magazine } \\
\text { Audience }\end{array}$ & $\begin{array}{l}\text { Readability of } \\
\text { advertisements }\end{array}$ & $\begin{array}{l}\text { Not correlated, } \\
\text { leading } \\
\text { experiments to } \\
\text { perceive ads } \\
\text { may be designed } \\
\text { to meet the } \\
\text { lowest education } \\
\text { level regardless } \\
\text { of what a } \\
\text { magazine's } \\
\text { general } \\
\text { audience's } \\
\text { education level } \\
\text { may be. }\end{array}$ & No \\
\hline $\begin{array}{l}\text { Thompson et al., } \\
2005\end{array}$ & $\begin{array}{c}\text { Usability } \\
\text { Capability } \\
\text { Expertise }\end{array}$ & $\begin{array}{c}\text { Low features } \\
\text { Medium features } \\
\text { High features }\end{array}$ & $\begin{array}{l}\text { High Features } \\
\text { decreased } \\
\text { usability; } \\
\text { Increased } \\
\text { capability and } \\
\text { expertise }\end{array}$ & $\begin{array}{l}\text { Some stimuli } \\
\text { had images, } \\
\text { some did not }\end{array}$ \\
\hline
\end{tabular}


Table 1 / cntd.

\begin{tabular}{ccccc}
\hline Tuch et al., 2009 & Recognition & Likert Scale 1 to & Low complexity & Some stimuli \\
Rate & 7 & had highest & had images, \\
& & recognition rate & some did not \\
& & &
\end{tabular}

with increased performance in search tasks, comprehension, and recall (Tuch et al. 2009).

Consumer characteristics influence the perception of complexity and complex designs can create both positive and negative associations. Knowledge can be a significant moderator for visual, technical, and lexical dimensions of complexity (Putrevu et al. 2004). Also, information-rich messages seem to be more effective for highly involved consumers, suggesting that those consumers were less likely to suffer from information overload and, hence, were persuaded by the information contained in more complex messages (Putrevu et al.). Dellaert and Stremersch (2005) and Eytam et al. (2017) further confirm that consumers are more willing to accept the complexity of a customized product if they perceive a higher product utility or functionality. Yet, high complexity may cause feature-fatigue because feature-laden products may frustrate users and reduce satisfaction (Goodman and Irmak 2013; Thompson et al. 2005). Negative feelings towards greater complexity may reduce purchase probabilities.

Characteristics associated with higher complexity such as irregular shapes, greater detail (such as visually rich photographs), and increased variety of objects increase the likelihood of higher order processing (Donderi 2006). However, higher complexity is not always seen as a positive. Orth and Wirtz (2014) sought to establish visual complexity effects on approach / avoidance behavior through processing fluency and perceived attractiveness of an environment. In their work, two stores were evaluated on their perceived complexity. The main result is that complexity has a significant negative effect on perceived attractiveness and on perceptual load. However, perceptual load (amount of distractor information) fully mediates the relationship between complexity and shopping experience. This confirms that complexity operates through perceptual load to negatively affect the shopping experience for consumers. In this case, more visually complex environments are detrimental to the shopping experience because of the increased load they place on customers (Orth et al. 2016).

\section{Design Complexity and Attention}

To process the visual information, visual attention must first be allocated to a stimulus, or sign (Kellaris and Machleit 2016; Tang 2020). This form of attention is related to processing ease and fluency (speed); for example, greater attention to complex words leads to shorter processing time (Rayner 2009). Complexity can influence visual attention negatively, as crowded shelf displays can disrupt shoppers' visual attention by slowing down the 
cognitive processing required to locate an item (Pieters et al. 2010; Clement et al. 2013). This cognitive load, where individuals monitor and try to gain control over their thoughts and mental effort when processing input, can deplete a person's attention capacity (Lavie 2000; Schwartz et al. 2013). When visual complexity increases so does mental processing effort. Gilbert et al. (1988) show that individuals who try to actively control their visual attention and ignore nuisance stimuli (e.g. crowded displays) perform worse on a subsequent task than subjects who view the same meaningless stimuli but do not actively try to ignore them. Therefore, complex display designs may impede consumer purchase choice because the effort to cognitively process the display distracts from the goal of the display - to motivate purchase.

\section{Eye Movement}

Eye movement is an indicator of visual attention, decision-making processes, and choice (Ares et al. 2014; Behe et al. 2017; Hepworth et al. 2010; Huddleston et al. 2018; Milosavljevic et al. 2012; Mundel et al. 2018; Werthmann et al. 2013). This information is collected in an objective, non-invasive manner by observing gaze behavior and computing metrics, such as fixation duration and fixation count ( $\mathrm{Vu}$ et al. 2016). Fixation duration is the length of visual stop on an object, while fixation count is the number of stops in a visual area of interest (AOI). For complex visual stimuli such as displays, eye fixations are necessary in identifying and cognitively processing objects (Chandon et al. 2009).

Humans are blind during physical eye movement (saccade), except for smooth pursuit saccade, an example of which would be watching a car drive past. "Visits" are a visual metric that include both saccades and fixations in a specific AOI. Given the inability to see during eye-movement, fixations, not visits, are the more common metric. Additionally, fixation count (FC) and total fixation duration (FD) are highly correlated. FC is the number of times a person views a specific area and FD is the sum of fixation times in a specific area of interest. If a subject had 10 fixations $(\mathrm{FC}=10)$ in a specific $\mathrm{AOI}$, each lasting 0.1 second, the FD is 1 second. Although the measures are related, they do highlight different aspects of visual attention, as where FC indicates the number of "looks" an area attracts FD is an aggregate measure of time in that area.

In consumer behavior contexts, eye-movements are thought to be controlled by top-down and bottom-up processes in choice tasks (Orquin and Loose 2013). Top-down processes refer to characteristics about the consumer, such as individual traits. Bottom-up factors, on the other hand, refer to characteristics about the stimulus, such as signs or products. Top-down and bottom-up factors contribute to attention and, thus, both affect meaning derived from the stimuli (Huddleston et al. 2015). Top-down information assessment is considered as goal-driven attention and bottom-up is commonly defined as stimulus-driven attention and is controlled by marketers who regulate the visual stimuli on displays (Corbetta and Shulman 2002).

The evidence linking FC to complexity is mixed. Huddleston et al. (2015) found a negative relationship between the FC and LTB in a retail center context while other studies have confirmed a positive relationship between visual complexity and FC (see Chassy et al. 2015; Wang et al. 2014). Interestingly, Wang et al. found that FD was similar for websites, despite varying degrees of complexity; however, for complex tasks on moderately complex websites, FD is greater. This could be attributed to load theory of attention, which explains how a person can filter unnecessary stimuli under conditions of high perceptual load (Wang et al. 2014). Van der Laan et al. (2015) investigate the effect of FD on choice and they found that the preferred choice was fixated upon longer. Thus, we hypothesize:

H1a: Signs classified as highly complex (vs. moderate or low) will have the highest FD;

H1b: Highly complex signs will have the greatest FC.

\section{Attractiveness}

Attractiveness, "the quality of being pleasing or appealing to the senses," is a subjective property, and several dimensions of attractiveness (aesthetics, arousal, functionality, and fluency) have been investigated in the context of product evaluation (Kellaris and Machleit 2016; "Attractiveness" 2020). Of these dimensions, aesthetics is a predictor of 
preference across all levels of visual complexity regardless of user type (Eytam et al. 2017). Thus, if a consumer finds an item to be attractive, then regardless of the level of packaging or signage complexity, the consumer will prefer that particular item. These aesthetic appraisals happen within a few seconds and a key driver of attractiveness is how fluently viewers are able to process the stimulus (Lindgaard et al. 2006; Mollerup 2015; Tractinsky et al. 2006; Reber, Wurtz, and Zimmermann 2004).

Fluency is the subjective experience of ease with which a person processes a stimulus and an important source of information (Reber, Wurtz, and Zimmermann 2004). Sometimes consumers misattribute the fluency to the stimulus and associate more fluent stimuli with greater attractiveness (Schwarz). In Puškarević et al. (2016), a study similar to Wedel and Pieters (2008), consumer attitude towards advertisements with different typeface figurations were evaluated on a five-point Likert scale using three variables: likeable, favorable, and interesting. Findings show that consumers pay attention to and find advertisements most attractive when the short verbal cues are depicted through rhetorical figuration, indicative of the observation that simple advertisements are most attractive (Puškarević et al. 2016). In this study, we use signage as an advertising format and hypothesize that:

$\mathrm{H} 2$ : Consumers will rate moderately complex signs as more attractive compared to simple or high-complexity signs;

H3a: Sign complexity is a predictor of Likeliness to Buy (LTB) a product from a display containing that sign;

H3b: More attractive signs will evoke a higher LTB;

$\mathrm{H} 3 \mathrm{c}$ : Greater visual attention to the number of elements in the display (FC) will evoke a greater LTB;

H3d: More visual attention through total time processing (FD) will indicate a greater LTB.

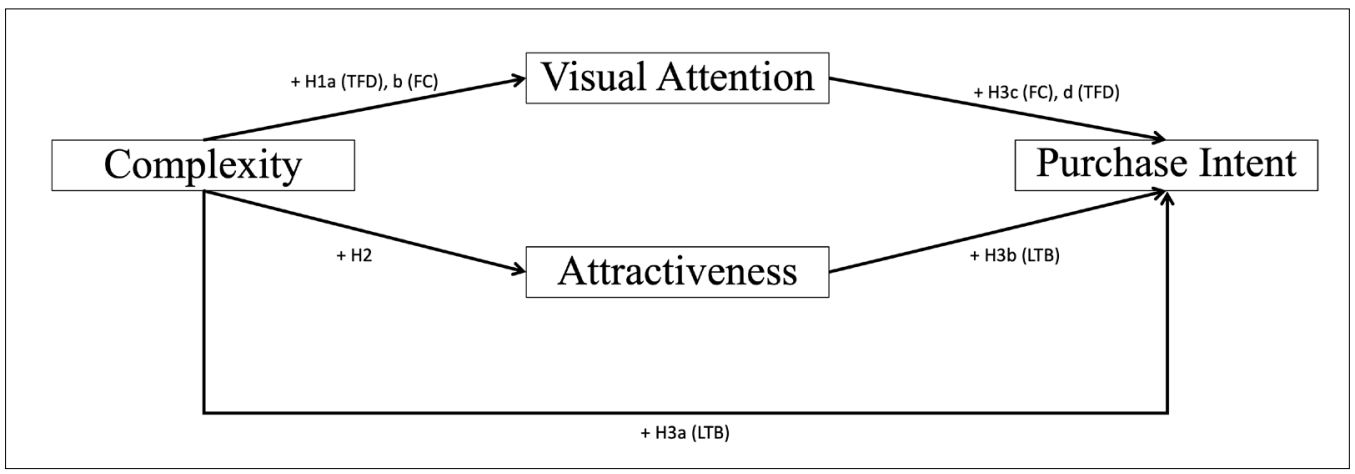

Interdisciplinary Journal of Signage and Wayfinding; Vol. 4, No. 2 (2020)
Figure 1 / Theoretical model predicting purchase intent showing hypotheses and measures 


\section{MATERIALS AND METHODS \\ Stimuli}

To develop the study stimuli, a selection of 105 images were taken from displays in U.S. garden retailer centers. This selection was designed to ensure a broad array of sign complexity, based on attributes described in Pieters et al. (2010), was present. A team of five raters gauged sign complexity based upon the following criteria: quantity of objects (many = complex), irregularity of objects (irregular $=$ complex), dissimilarity of objects $($ dissimilar $=$ complex), detail of objects (detail $=$ complex), asymmetry of object $($ asymmetric $=$ complex), and irregularity of object arrangement (irregular $=$ complex). The raters were trained independently, and each evaluated all of the images; their ratings were averaged and subject to mean separation by SPSS (data available upon request). Of the 105 images, 5 low, medium, and high complexity signs were then selected for the study, totaling 15 .

Low complexity signs have mean scores at least one standard deviation $(S D)$ above the minimum (1.00) and a $S D$ of raters less than two-thirds the overall $S D$ (1.12). Moderate complexity signs are scored at one $S D$ above the mean (0.560) and a $S D$ of the raters less than $2 / 3$ of the overall $S D$ (1.12). High complexity signs have $1 S D$ under the maximum and a $S D$ of the raters less than $2 / 3$ of the overall $S D$ (1.12). To further reduce the number of images, those with the lowest standard deviations and with means closest to the overall minimum, mean, and maximum are chosen for the low, moderate, and high complexity categories, respectively. Figure 2 (below) shows the stimuli in each complexity level.

Images were then randomized and incorporated into the Tobii X1 Light Eye Tracker software and pre-tested with several subjects prior to study implementation to beta-test for subject fatigue and experiment timing. The eye-tracking camera was mounted on the study's computer monitor and the images were located centrally on the screen.

\section{Procedure}

To test our hypotheses, an experiment with a protocol and instrument approved by the University Committee on Research Involving Human Subjects was conducted using the selected signs (IRB\# x18-1348e Category: Exempt 2). Collected data were analyzed with SAS System for Windows (Version 9.4). After visually evaluating each image, subjects rated their likeliness to buy (LTB) a product from a display and sign attractiveness. Attractiveness, consisting of a three-item scale (likeable, beautiful, and attractive) are measured using 5-point Likert scales. Likeliness to buy (LTB) is measured using a 11-point Juster scale $(0=$ no probability of purchase, $10=$ certain probability of purchase). At the end of the experiment subjects complete a separate computer-based questionnaire (Qualtrics Online Survey Software) containing sociodemographic information.

Data were collected in the fall of 2018 at two large American universities and 


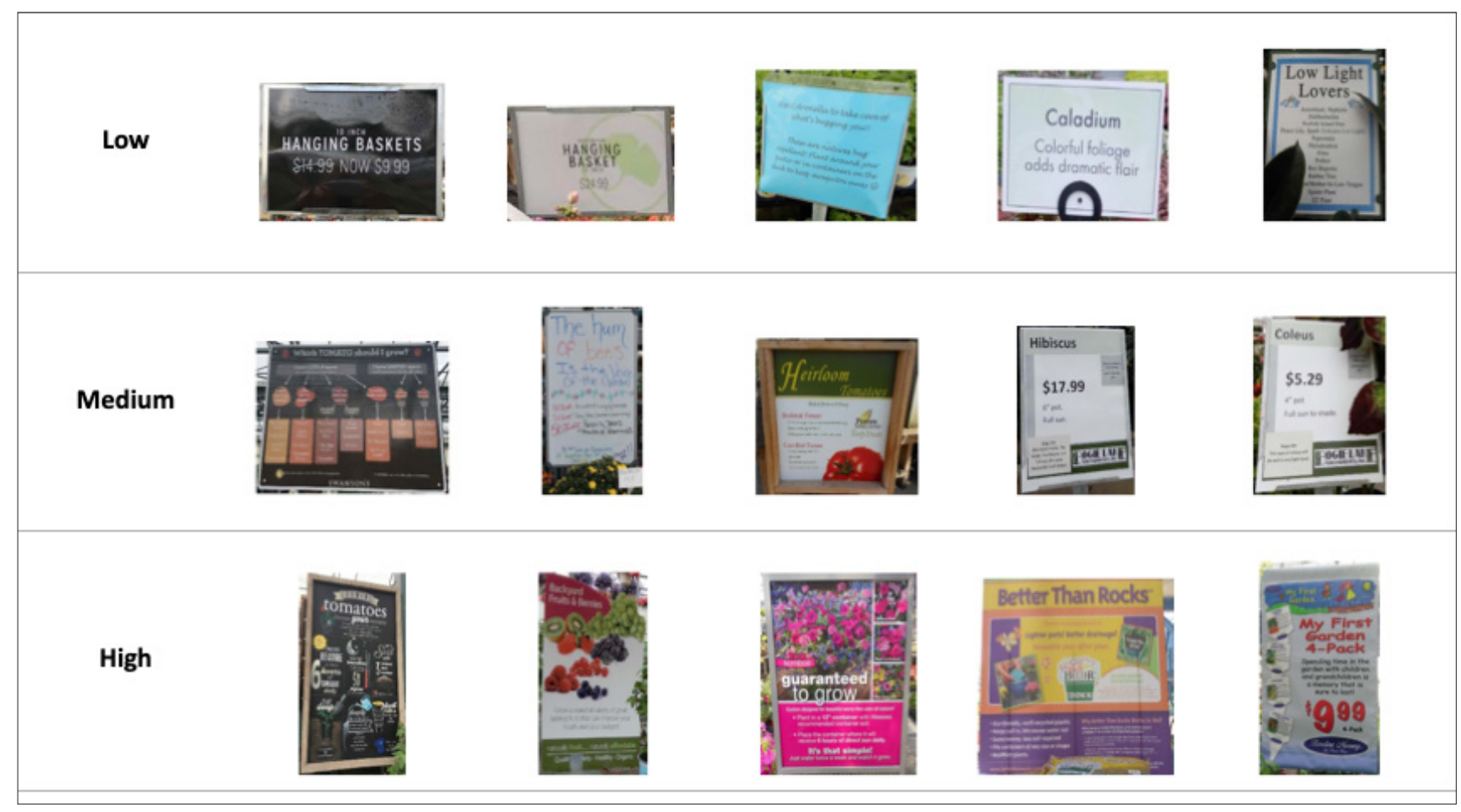

Figure 2 / Signs within experiment displayed by complexity category

subjects, largely non-student, were recruited through email invitations sent to departmental panels. Upon arrival at the testing location, subjects were greeted, provided with an informed consent form, and paid a $\$ 10$ incentive; they then conducted the eye-tracking portion of the study, followed by a purchase and demographic questionnaire.

\section{Eye-movement tracking process}

Once seated at the Tobii eye-tracking device, the eye-tracker was calibrated to the subjects (Behe et al. 2013). The study began with instruction and practice slides. Each of the 15 stimuli were preceded by a 2 second bull's eye to reposition the subject's gaze to one of the 4 corners of the screen to avoid central gaze bias. In addition to the LTB and attractiveness ratings, two visual measures of attention, fixation count (FC) and fixation duration (FD) with FD calibrated to a hundredth of a second, were extracted.

\section{Sample Characteristics}

The study sample is $73 \%$ female $(S D=0.44)$ and has a mean age of 34 years $(S D=11.92)$. There is an average of 2 adults per household (mean $=2.05, S D=$ 0.79 ) and $75 \%$ of the households have at least 1 child (mean $=0.75, S D=0.02$ ). The percentage of subjects who completed a 4-year college degree or greater is $80.2 \%$ of the sample (mean $=5.18 ; S D=1.36$ ). Household income averages $\$ 62,559(S D=49.21)$. Ninety-five percent of the population is plant purchasers.

Regarding the participants' plant purchase habit, the three most purchased plant categories are herbs $(58 \%$, mean $=0.58, S D=0.5)$, indoor foliage plants $(49 \%$, mean $=0.04, S D=0.50)$, and annuals $(44 \%$, mean $=0.44, S D=0.5)$. The average subject purchases plants in two of the plant categories listed (mean 
$=2.42, S D=1.56)$. These values are consistent with national statistics on plant purchases (Butterfield and Baldwin 2015).

Analyses

Sign complexity is the independent variable and the dependent variables are visual attention measures (fixation count and fixation duration), sign attractiveness, and likeliness to buy (LTB). Sign attractiveness is measured using a three-item construct: "How attractive is this sign?" $(0=$ very unattractive, $5=$ very attractive) "How beautiful is this sign?" ( $0=$ not at all beautiful, $5=$ very beautiful) and "How likeable is this sign?" ( $0=$ very unlikeable, $5=$ very likeable), whereas LTB is measured using an 11 -point Juster scale $(0=$ no probability of purchase, $10=$ certain probability of purchase) (Juster 1966). The Principal Component Analysis of the three items used to measure attractiveness accounts for $85 \%$ of the variance (Cronbach Coefficient Alpha Standardized $=0.9281)$. The three items have loadings over 0.600 (Attractive $=0.9519$, Beautiful $=0.9420$, Likeable $=$ 0.9111 ) and are used as a single construct to measure attractiveness.

A series of one-way ANOVA analyses, by complexity, was conducted to test H1a, H1b, and H2. Differences between sign complexity levels are tested with Tukey's HSD. To test all parts of $\mathrm{H} 3$, a regression assessed impact of sign complexity, sign attractiveness, and visual measures (FC and FD) has on LTB.

\section{RESULTS}

Hypothesis 1a: Signs classified as highly complex

(v. moderate or low) will have the highest FD. Signs with high and moderate complexity have a similar FD $\left(6.1_{\text {high }}\right.$ vs. $5.8_{\text {moderate }}$ ) which was greater than signs classified as low complexity (4.7 low $)$ (see Table 2). Thus, Hypothesis 1a is partially supported.

Hypothesis 1b: Highly complex signs will have the greatest FC.

In partial support of Hypothesis $1 \mathrm{~b}$, signs categorized as highly complex have a greater FC as compared to signs categorized as low complexity $\left(29.7_{\text {high }}\right.$ vs. 24.1 (ow), but FC in high complexity signs is similar to signs classified as moderately complex $\left(28.9_{\text {moderate }}\right)$ (see Table 2).

Hypothesis 2: Consumers will rate moderately complex signs as more attractive compared to simple or high-complexity signs.

Using participants' composite rating of sign attractiveness for each of the 15 signs, results show that signs classified as highly complex have the greatest attractiveness (mean $=0.678, \mathrm{SE}=0.02)$ compared to low (mean $=0.134, \mathrm{SE}=0.03$ ) or moderate complexity signs (mean $=-0.659, \mathrm{SE}=0.04)$. This is confirmed with a Tukey's HSD (High v. Low $=1.337, \mathrm{p}=0.0001$; Moderate v. Low $=0.790, p=0.0001 ;$ High v. Moderate $=0.554$, $\mathrm{p}=0.0001$ ). Thus, Hypothesis 2 is not supported; contrary to this hypothesis, highly complex signs are rated as most attractive while low complexity signs are rated as least attractive.

Hypothesis 3: Sign complexity, sign attractiveness, $F D$, and FC are predictors of LTB.

To test Hypotheses 3a-3d, we examined both simple pairwise correlations (Table 3 ) and conducted a regression. Sign Complexity $(\beta=-0.1936)$, Attractiveness $(\beta=1.8868)$, FC $(\beta=0.0093)$, and $\mathrm{FD}(\beta=-0.0404)$ are all predictors of LTB, however, sign complexity and FD are inversely correlated to likeliness to buy. Therefore, regression results support Hypothesis $3 \mathrm{~b}$ and 3c. Approximately two-thirds of the observed variation in LTB are explained by this model, with attractiveness having the greatest explanatory power $\left(\mathrm{R}^{2}=0.6842\right)$.

Because FD and sign complexity were negatively related to purchase intention, a mediation effect of FD is suspected and following Baron and Kenny's (1986) recommendation for testing mediation, a series of regressions was conducted. First, we found that FC is positively related to $\mathrm{FD}(\mathrm{F}=13342.08, \mathrm{p}=0.0001)$. Next, regressing $\mathrm{FC}$ on purchase intention uncovered a positive result $(\mathrm{F}=20.4098, \mathrm{p}=0.0001)$, as did regressing FD on purchase intention $(F=17.5186, p=0.0001)$. Simply stated, both FC and FD independently increased purchase intention, however, regressing FC and FD on purchase intention showed that FD was no longer a significant predictor of purchase intention (FC: $\mathrm{F}=2.8856$, 


\section{Fixation Count}

Sign Feature Complexity

Level

Low

Medium

High

(DF) F-value, $p$-value

${ }^{1}$ Different letters within columns indicate significant differences of means at $\alpha=0.05$.

(SAS for Windows, version 9.4, SAS Institute Inc., Cary, North Carolina).

Table 3 / Pairwise correlations of independent variables

\begin{tabular}{llcc}
\hline Variable & \multicolumn{1}{c}{ By Variable } & $\begin{array}{c}\text { Correlation } \\
\left(\mathbf{r}^{2}\right)\end{array}$ & $\begin{array}{c}\text { Significance Level } \\
(\boldsymbol{p} \text {-value })\end{array}$ \\
\hline FD & Complexity & 0.0887 & 0.0002 \\
FC & Complexity & 0.0357 & 0.0005 \\
FC & TFD & 0.9390 & 0.0001 \\
Attractiveness & Complexity & 0.5327 & 0.0001 \\
Attractiveness & FD & 0.1233 & 0.0001 \\
Attractiveness & FC & 0.1201 & 0.0001 \\
\hline
\end{tabular}

Table 4 / Regression Analysis of Likeliness to Buy (LTB) by Attractiveness, Sign Complexity, Fixation Count, and Fixation Duration

\begin{tabular}{|c|c|c|c|c|}
\hline Attribute and Level & $\begin{array}{c}\text { Standardized } \\
\text { Beta Estimate } \\
\text { (SE) }\end{array}$ & Num DF & F value & $\operatorname{Pr}>$ F \\
\hline Intercept & $6.0593(0.1012)$ & 1 & 59.87 & 0.0001 \\
\hline Complexity & $-0.1936(0.0420)$ & 1 & 21.2634 & 0.0001 \\
\hline Attractiveness & $1.8868(0.0346)$ & 1 & 2966.357 & 0.0001 \\
\hline $\mathrm{FC}$ & $0.0093(0.0044)$ & 1 & 4.5451 & 0.0331 \\
\hline FD & $-0.0404(0.0202)$ & 1 & 4.0171 & 0.0452 \\
\hline $\mathrm{AICC}$ & 5762.817 & & & \\
\hline $\mathrm{BIC}$ & 5795.716 & & & \\
\hline $\mathrm{R}^{2}$ & 0.6842 & & & \\
\hline
\end{tabular}

Notes: $n=1792 ;$ F-value $=967.8213 ;$ p-value $=<0.0001$

(SAS for Windows, version 9.4, SAS Institute Inc., Cary, North Carolina) 
$\mathrm{p}=0.0895$; FD: $\mathrm{F}=0.0240, \mathrm{p}=0.8770)$, indicating that FD mediates the effect of FC on purchase intention.

To summarize, subjects spent more time (higher FD) viewing high and moderately complex signs and across more areas (higher FC) as compared to lower complexity signs. Highly complex signs were found most attractive, with moderately and then low complexity signs following. A negative relationship between sign complexity and FD on purchase intention exists, meaning that lower complexity and a shorter glance increased purchase intention. However, there was a positive relationship between attractiveness and FC on purchase intention, indicating that a more aesthetically pleasing sign drew more looks increasing purchase intention. The series of regression analyses shows that FD mediates the relationships between FC and purchase intention, meaning that shorter viewing time decreased the number of possible areas at which to look or pieces of information that could be acquired.

\section{DISCUSSION}

The objective of this study is to explore the relationship between sign complexity, visual attention, perceived attractiveness of signage, and likeliness to buy. Pieters et al's (2010) complexity criteria are used by trained judges to characterize low, medium, and high complexity signs. Previous studies report that moderate complexity is most appealing to consumers, whereas our findings show the highest complexity level is rated as most attractive (Berlyne 1974; Pieters et al.). This could be the result of study participants finding greater functionality in the high-complexity signs (i.e. more salient information) and low functionality with low complexity signs and because plants are living products that are expected to grow and change, consumers may require more information before investing in a perishable product to reduce a perceived risk (Etyam 2017; Behe and Fry 2019). In this purchase context, and contrary to Thompson et al. (2005), reducing sign functionality is not desired. Also, consumers with an existing information base may need more detailed information provided by complex signage as a basis for comparison against that existing knowledge (Putrevu et al. 2004). This is confirmed by previous work that describes how consumers are more willing to accept the complexity of a customized product if that product allows them to achieve a higher product utility or functionality (Dellaert and Stremersch 2005).

The study participants found greater visual appeal in the higher complexity signs, potentially the result of finding highly complex signs more attractive because they have greater aesthetic appeal (see Janiszewski and Meyvis 2001; Reber et al. 2004a; 2004b). While we did not measure fluency, it is possible that consumers found greater fluency, a subjective measure based on the individuals' experience with the stimulus, in the combination of text and images present in highly complex signs. Since all the participants have previously purchased plants, they may have found greater fluency in highly complex signs because of their familiarity with these types of signs or products or expected to see this type of sign in a garden store or retail center. A relation- 
ship between familiarity and perceived attractiveness has been found in previous work (Peskin and Newell 2004). Future studies should investigate the relationships between fluency, familiarity, and attractiveness, and in turn, the ability of these constructs to predict purchase intention.

Contrary to Hypotheses 3a-3d, complexity is inversely related to LTB (purchase intention), so, while the respondents found more complex signs to be more attractive, this did not result in higher purchase intention. A seeming disconnect, this aligns with Iyengar and Lepper's (2000) study, which finds that consumers are more attracted to a larger product display but are more likely to purchase from a limited product display. In forming purchase intention some information may be necessary, but too much information may lead to excessive higher order processing which in turn decreases purchase intention (Donderi 2006).

Hypotheses $1 \mathrm{a}$ and $1 \mathrm{~b}$, which explore visual attention and sign complexity, is supported; high complexity signs garnered more visual attention (i.e. higher fixation count and total fixation duration). This finding is consistent with Pieters et al. (2010), who confirm that advertising complexity increased visual attention, and with Morrison and Dainoff (1972), who show that greater sign complexity resulted in longer looking time.

A positive relationship exists between likeliness to buy and fixation count, thereby indicating that participants allocate more "looks" to the point of purchase signs. This allocation of visual attention supports Behe et al. (2014), in that consumers seek out and find desired or useful information faster when it is important to them, almost as if they unconsciously sort through the information present on the sign to "cherry-pick" what would help them make a purchase decision. This "cherry picking" would be supported in the observed higher FC. Further, the inverse relationship between fixation duration and likeliness to buy refutes previous studies (Atalay 2012; Glaholt and Reingold 2009; Krajbich 2010).

Finally, the study also found a mediation effect of FD on FC predicting purchase intention. Intuitively, a person would have fewer "looks" if they were not looking as long. Maughn et al. (2007) reported that the study participants liked a bus advertisement more if they looked at it longer. Yet, the evidence in the present study shows that the time spent viewing a sign (FD) limits how many individual pieces of information (FC) can be gleaned from it.

\section{CONCLUSIONS}

The impetus for this study is the application of Pieters et al.s (2010) visual complexity criteria to a retail setting (garden centers) using point of purchase signage. We found that moderate / high complexity signs captured more visual attention (FD) and motivated consumers to view more areas in the signs (FC), which was similar to Chassy et al. (2015). Based on previous research, we predicted that consumers would prefer moderately complex signs over simple/highly complex signs, but this was not the case. Highly complex signs are perceived as more attractive, but greater attractiveness did not enhance purchase intention. Perceived attractiveness and complexity are positively related, i.e. more elements created a richer image and a more pleasing view, however, simply finding a complex sign as attractive did not stimulate purchase intention. More information, while creating a more attractive image, could have cluttered the path to a purchase decision; not all of the information on a complex sign was useful to all of the study subjects.

The challenge for a retailer is to identify the information that is most useful to a broad customer base and strike a balance between information and quality. For example, price as a search attribute is quite often an important, if not essential, input to the purchase decision and needs to be included in a display sign. In this study, respondents were not asked to identify what information was useful, but future work should seek to capture usefulness of information and to whom it matters most. A perceived overabundance of information in the high complexity signs actually reduced the likelihood of purchase intention, but it is unknown what information is superfluous. For example, highlighting experience attributes, such as a tomato's flavor or basil's aroma, may be helpful in a purchase decision to some customers-others though may seek out credence attributes and would rather know if the plant was grown organically or from a local producer. Teas- 
ing out the underpinnings of this intricate relationship should be a focus of future research.

From a managerial standpoint, the inverse relationship between likeliness to buy and complexity suggest that low complexity signs are appropriate for impulse purchases where the seller is trying to encourage a quick decision (Hausman 2000). In light of emergent text-based (SMS) marketing, there may be a mechanism to send a potential customer the customized information that reduces the perceived information clutter unintentionally communicated by highly complex signs. Future research should focus on the sign element combinations that lead to perceived attractiveness, which, as determined in this study, leads to purchase intention. For example, will using text to highlight the benefits (vs. features) of a plant or any other product resonate with consumers (Hall and Knuth 2019a; 2019b; 2019c)? How should images be integrated into the point of purchase signage? Will information-rich messaging create cognitive overload for consumers? What is the correct balance between information and images to enhance both perceived attractiveness and purchase intention? Another fruitful avenue for study is to measure both the perceived fluency and cognitive load that high and low complexity signs present and then analyze these constructs in light of purchase intention.

One potential limitation to this study is the lack of product images on low complexity signs. Since the complexity criteria for this study originated in Pieters and Wedel (2010), where the number of images were one of the evaluation criteria, the number of images for these signs were minimized. Choices of signage to reflect the different complexity levels in the main study were based on the mean / standard deviation of the judges' responses. As a result, some signs were primarily text and without images of the plant or produce and may have altered the sign's complexity rating. Perhaps also, other experts would have assessed the signs differently. Future studies should investigate a broader array of products and signs to determine how perceptions vary by product type or also include a complexity rating by participants.

In addition to the research questions previously mentioned, future research could investigate in what circumstances low or high complexity signs might be more effective in eliciting purchase intention (e.g. impulse purchases). For premium price points or for featured products a more complex sign could be more effective in motivating consumers to learn more about the product and dive into the details. Typically, in-store signs present other dimensions such as brand credibility and readability, which may influence perceived attractiveness, complexity and therefore, purchase intention. Top down factors (e.g. expertise, time, pressure) might also influence these constructs and will be considered as a future research area. 


\section{REFERENCES}

Anderson, R. E. and Jolson, M. A. (1980). Technical wording in advertising: Implications for market segmentation. Journal of Marketing 44(1), 57-66.

Ares, G., Mawad, F., Giménez, A. and Maiche, A. (2014). Influence of rational and intuitive thinking styles on food choice: Preliminary evidence from an eye-tracking study with yogurt labels. Food Quality and Preference 31, 28-37.

Atalay, A. S., Bodur, H. O., and Rasolofoarison, D. (2012). Shining in the center: Central gaze cascade effect on product choice. Journal of Consumer Research 39(4), 848-866.

"Attractiveness." (2020). Oxford Online Dictionary.

Baron, R. M. and Kenny, D. A. (1986). The moderator-mediator variable distinction in social psychological research: Conceptual, strategic, and statistical considerations. Journal of Personality and Social Psychology 51, 1173-1182.

Behe, B. K., Campbell, B. L., Khachatrayn, H., Hall, C. R., Dennis, J. H., Huddleston, P. T., and Fernandez, R. (2014). Incorporating eye tracking technology and conjoint analysis to better understand the green industry consumer. HortScience 49(12), 1550-1557.

Behe, B. K. and Fry, J. (2019). How do Plant Guarantees Reduce Consumer Risk Perceptions? Journal of Risk Research, 1-17.

Behe, B. K., Huddleston, P. T., Hall, C. R., Khachatryan, H., and Campbell, B. (2017). Do real and fictitious plant brands differ in brand recognition, awareness, purchase intention, and visual activity? HortScience 52(4), 612-621.

Behe, B. K., Fernandez, R. T., Huddleston, P. T., Minahan, S., Getter, K. L., Sage, L., and Jones, A. M. (2013). Practical field use of eye-tracking devices for consumer research in the retail environment. HortTechnology 23(4), 517-524.

Berlyne, D. E. (1974). Studies in the new experimental aesthetics. Washington, DC: Hemisphere.

Butterfield, B. and Baldwin, I. (2015). National Gardening Survey. Williston, VT: National Gardening Association.

Chandon, P., Hutchinson, J. W., Bradlow, E. T., and Young, S. H. (2009). Does in-store marketing work? Effects of the number and position of shelf facings on brand attention and evaluation at the point of purchase. Journal of Marketing 73(6), 1-17.

Chassy, P., Lindell, T. A. E., Jones, J. A., and Paramei, G. V. (2015). A relationship between visual complexity and aesthetic appraisal of car front images: An eye-tracker study. Perception 44(8-9), 1085-1097.

Clement, J., Kristensen, T., and Grønhaug, K. (2013). Understanding consumers' in-store visual perception: The influence of package design features on visual attention. Journal of Retailing and Consumer Services 20(2), 234-239.

Corbetta, M. and Shulman, G. L. (2002). Control of goal-directed and stimulus-driven attention in the brain. Nature Reviews in Neuroscience 3(3), 201-215.

Dellaert, B. G. and Stremersch, S. (2005). Marketing mass-customized products: Striking a balance between utility and complexity. Journal of Marketing Research 42(2), 219-227.

Donderi, D. C. (2006). Visual complexity: A review. Psychological Bulletin 132(1), 73-97.

Eytam, E., Tractinsky, N., and Lowengart, O. (2017). The paradox of simplicity: Effects of role on the preference and choice of product visual simplicity level. International Journal of Human-Computer Studies 105, 43-55.

Geissler, G. L., Zinkhan, G. M., and Watson, R. T. (2006). The influence of home page complexity on consumer attention, attitudes, and purchase intent. Journal of Advertising 35(2), 69-80.

Gilbert, D. T., Krull, D. S., and Pelham, B. W. (1988). Of thoughts unspoken: Social inference and the self-regulation of behavior. Journal of Personality and Social Psychology 55(5), 685.

Glaholt, M. G. and Reingold, E. M. (2009). The time course of gaze bias in visual decision tasks. Visual Cognition 17(8), 1228-1243.

Goodman, J. K. and Irmak, C. (2013). Having versus consuming: failure to estimate usage frequency makes consumers prefer multi-feature products. Journal of Marketing Research 50(1), 44-54.

Hall, C. and Knuth, M. (2019a). An update of the literature supporting the well-being benefits of plants: A review of the emotional and mental health benefits of plants. Journal of Environmental Horticulture 37(1), 30-38.

Hall, C. and Knuth, M. (2019b). An update of the literature supporting the well-being benefits of plants: Part 2 Psychological health benefits. Journal of Environmental Horticulture 37 (June), 63-73.

Hall, C. and Knuth, M. (2019c). An Update of the Literature Supporting the Well-Being Benefits of Plants: Part 3-Social Benefits. Journal of Environmental Horticulture 37(4), 136-142. 
Hausman, A. (2000). A multi-method investigation of consumer motivations in impulse buying behavior. Journal of Consumer Marketing 17(5), 403-426.

Hepworth, R., Mogg, K., Brignell, C., and Bradley, B. (2010). Negative mood increases selective attention to food cues and subjective appetite. Appetite 54(1), 134-142.

Huddleston, P. T., Behe, B. K., Driesener, C., and Minahan, S. (2018). Inside-out: Using eye-tracking to investigate search-choice in the retail environment. Journal of Retailing and Consumer Services 43, 85-93.

Huddleston, P. T., Behe, B. K., Minahan., S. M., and Fernandez, R. T. (2015). Seeking Attention: A study of in-store merchandise displays using eye-tracking. International Journal of Retail and Distribution Management 43(6), 561-574.

Iyengar, S. S. and Lepper, M. R. (2000). When choice is demotivating: Can one desire too much of a good thing? Journal of Personality and Social Psychology 79(6), 995-1006.

Janiszewski, C. and Meyvis, T. (2001). Effects of brand logo complexity, repetition, and spacing on processing fluency and judgment. Journal of Consumer Research 28(1), 18-32.

Juster, F. T. (1966). Consumer buying intentions and purchase probability: An experiment in survey design. Journal of the American Statistical Association 61(315), 658-696.

Kellaris, J. J. and Machleit, K. A. (2016). Signage as marketing communication: a conceptual model and research propositions. Interdisciplinary Journal of Signage and Wayfinding 1(1), 1-17.

Krajbich, I., Armel, C., and Rangel, A. (2010). Visual fixations and the computation and comparison of value in simple choice. Nature Neuroscience 13(10), 1292.

Lavie, N. (2000). Selective attention and cognitive control: Dissociating attentional functions through different types of load. Attention Performance XVIII, 175-194.

Lindgaard, G., Fernandes, G., Dudek, C., and Brown, J. (2006). Attention web designers: you have 50 milliseconds to make a good first impression! Behavioral Information Technology 25(2), 115-126.

Maughan, L., Gutnikov, S. and Stevens, R. (2007) Like more, look more. Look more, like more: The evidence from eye-tracking. Journal of Brand Management 14, 335-342.

Milosavljevic, M., Navalpakkam, V., Koch, C., and Rangel, A. J. (2012). Relative visual saliency differences induce sizable bias in consumer choice. Journal of Consumer Psychology 22(1), 67-74.

Mollerup, P. (2015). Simplicity: A Matter of Design. Amsterdam: BIS.

Morrison, B. J., and Dainoff, M. J. (1972). Advertisement complexity and looking time. Journal of marketing research 9(4), 396-400.

Mundel, J., Behe, B. K., and Huddleston, P.T. (2018). An eye tracking study of minimally branded products: Hedonism and branding as predictors of purchase intention. Journal of Product and Brand Management 27(2), 146-157.

Orquin, J. L. and Loose, S. M. (2013). Attention and choice: A review on eye movements in decision making. Acta Psychologica 144(1), 190-206.

Orth, U. R. and Crouch, R. C. (2014). Is beauty in the aisles of the retailer? Package processing in visually complex contexts. Journal of Retailing 90(4), 524-537.

Orth, U. R. and Wirtz, J. (2014). Consumer processing of interior service environments: the interplay among visual complexity, processing fluency, and attractiveness. Journal of Service Research 17(3), 296-309.

Orth, U. R., Wirtz, J. and McKinney, A. (2016). Shopping experiences in visually complex environments: a self-regulation account. Journal of Service Management 27(2), 194-217.

Peskin, M. and Newell, F. N. (2004). Familiarity breeds attraction: Effects of exposure on the attractiveness of typical and distinctive faces. Perception 33(2), 147-157.

Pieters, R., Wedel, M., and Batra, R. (2010). The stopping power of advertising: Measures and effects of visual complexity. Journal of Marketing 74(5), 48-60.

Puškarević, I., Nedeljković, U., Dimovski, V., and Možina, K. (2016). An eye tracking study of attention to print advertisements: Effects of typeface figuration. Journal of Eye Movement Research 9(5), 1-18.

Putrevu, S., Tan, J., and Lord, K. R. (2004). Consumer responses to complex advertisements: The moderating role of need for cognition, knowledge, and gender. Journal of Current Issues and Research in Advertising 26(1), 9-24. 
Rayner, K. (2009). Eye movements and attention in reading, scene perception, and visual search. The Quarterly Journal of Experimental Psychology 62(8), 1457-1506.

Reber, R., Schwarz, N., and Winkielman, P. (2004). Processing fluency and aesthetic pleasure: Is beauty in the perceiver's processing experience? Personality and Social Psychology Review 8(4), 364-382.

Reber, R., Wurtz, P., and Zimmermann, T.D. (2004). Exploring "fringe" consciousness: The subjective experience of perceptual fluency and its objective bases. Consciousness and Cognition 13(1), 47-60.

Schwartz, R. N., Milne, C., Homer, B. D., and Plass, J. L. (2013). Designing and implementing effective animations and simulations for chemistry learning. In: Pedagogic Roles of Animations Simulations in Chemistry Courses, eds J. Suits and M. Sanger. Washington, DC: American Chemical Society.

Schwarz, N. (2004). Metacognitive experiences in consumer judgment and decision making. Journal of Consumer Psychology 14(4), 332348.

Shuptrine, F. K. and McVicker, D. D. (1981). Readability levels of magazine ads. Journal of Advertising Research 21(5), 45-51.

Tang, M. (2020). Analysis of signage using eye-tracking technology. Interdisciplinary Journal of Signage and Wayfinding 4(1), 61-72.

Thompson, D. V., Hamilton, R. W., and Rust, R. T. (2005). Feature fatigue: When product capabilities become too much of a good thing. Journal of Marketing Research 42(4), 431-442.

Tractinsky, N., Cokhavi, A., Kirschenbaum, M., and Sharfi, T. J. (2006). Evaluating the consistency of immediate aesthetic perceptions of web pages. International Journal of Human-Computer Studies 64(11), 1071-1083.

Tuch, A. N., Bargas-Avila, J. A., Opwis, K., and Wilhelm, F. H. (2009). Visual complexity of websites: Effects on users' experience, physiology, performance, and memory. International Journal of Human-Computer Studies 67(9), 703-715.

van der Laan, L. N., Hooge, I. T., De Ridder, D. T., Viergever, M. A., and Smeets, P. A. (2015). Do you like what you see? The role of first fixation and total fixation duration in consumer choice. Food Quality and Preference 39, 46-55.

Vu, T. M. H., Tu, V. P., and Duerrschmid, K. (2016). Design factors influence consumers' gazing behaviour and decision time in an eye-tracking test: A study on food images. Food Quality and Preference 47, 130-138.

Wang, Q., Sang, S., Liu, M., Cao, Z., and Ma, Q. (2014). An eye-tracking study of website complexity from cognitive load perspective. Decision Science 62, 1-10.

Wedel, M. and Pieters, R. (2008). Eye tracking for visual marketing. Foundations and Trends in Marketing 1(4), 231-320.

Werthmann, J., Roefs, A., Nederkoorn, C., and Jansen, A. J. (2013). Desire lies in the eyes: attention bias for chocolate is related to craving and self-endorsed eating permission. Appetite 70, 81-89. 